\title{
Cartilage Appearance Using an Environmental Scanning Electron Microscope
}

\author{
SANTIAGO SUSO, ${ }^{1}$ JOSEP M. SEGUR, ${ }^{1}$ JOSE A. CARBONELL, ${ }^{1}$ \\ JOSE M. MANERO, ${ }^{2}$ and JOSE A. PLANELL ${ }^{1}$
}

\begin{abstract}
Because of technical principles, samples to be observed with electron microscopy need to be fixed in a chemical process and exposed to vacuum conditions that can produce some changes in the morphology of the specimen. The aim of this work was to obtain high-resolution images of the fresh articular cartilage surface with an environmental scanning electron microscope (ESEM), which is an instrument that permits examination of biological specimens without fixation methods in a 10 Torr chamber pressure, thus minimizing the risk of creating artifacts in the structure. Samples from weight-bearing areas of femoral condyles of New Zealand white rabbits were collected and photographed using an ESEM. Images were analyzed using a categorization based in the Jurvelin classification system modified by Hong and Henderson. Appearance of the observed elevations and depressions as described in the classification were observed, but no fractures or splits of cartilage surface, thought to be artifacts, were detected. The ESEM is a useful tool to obtain images of fresh articular cartilage surface appearance without either employing fixation methods or exposing the specimen to extreme vacuum conditions, reducing the risk of introducing artifacts within the specimen. For all these reasons it could become a useful tool for quality control of the preservation process of osteochondral allografting in a bank of musculoskeletal tissues.
\end{abstract}

\section{INTRODUCTION}

$\mathbf{S}$ INCE ITS INTRODUCTION in the market in 1965, the scanning electron microscope (SEM) has been frequently used in the study of the morphological characteristics of the articular cartilage surface. ${ }^{1-5}$

However, despite the amount of information obtained with this instrument the cartilage surface anatomy still remains controversial, perhaps because of technical variations of the equipment, specimens, or procedures between authors. 6,7

To observe a biological sample with a conventional electron microscope it must be fixed to preserve the structure of tissues with minimum alteration from the living state with regard to volume, morphology, and spatial relationships, and simultaneously protect the specimens against subsequent treatments like vacuum and exposure to the electron beam. Nevertheless, these methods may produce changes in the morphology of the specimen. ${ }^{8}$

The environmental SEM (ESEM) is an innovation in scanning microscopes. It was specifically designed to study samples that cannot be exposed to fixation techniques or extreme conditions like the microscope's chamber vacuum. ${ }^{9}$

The aim of this work was to study the appearance of fresh articular cartilage surface using the ESEM in order to obtain high-resolution images of specimens without fixation methods at a 10 Torr chamber pressure, thus

\footnotetext{
${ }^{1}$ Bank of Musculoskeletal Tissues, Transplant Services Foundation, Hospital Clínic de Barcelona, University of Barcelona, Barcelona, Spain.

${ }^{2}$ Center for Biomedical Engineering Research, Politechnical University of Catalonia, Barcelona, Spain.
} 
minimizing the risk of creating artifacts in the structure.

\section{MATERIALS AND METHODS}

\section{Animal model}

After authorization was received from the Ethical Committee for Animal Research of the University of Barcelona, Barcelona, Spain, five New Zealand female white rabbits (mean body weight $3.5 \mathrm{~kg}$, age 10-12 months) were euthanized. Knee joints were harvested by transection at the proximal femur and the distal tibia. Soft tissue and muscle were removed from each knee, and it was opened at the joint capsule, taking care not to damage the cartilage surface. A cartilage disk $(5 \mathrm{~mm})$ was collected with a trephine from the load-bearing areas of the medial femoral condyle. The time elapsing between the euthanization and the collection of the cartilage always was less than $2 \mathrm{~h}$.

\section{ESEM examination}

Each cartilage disk was then positioned on a stub and observed with an ESEM (ElectroScan XL30 ESEM-FEG; FEI Co., Hillsboro, OR), at $276.65 \mathrm{~K}$, and an accelerating voltage of $10 \mathrm{kV}$, making photographs following a sinusoidal path at 10 Torr of chamber pressure.

In a pilot study the articular surfaces of two freshly obtained rabbit knees underwent systematic ESEM examination and photography with primary magnifications of $250 \times, 500 \times$, and $1,000 \times$. After investigation and evaluation of the pictures it was decided that the primary magnification for the present method of analysis was $250 \times$. Under these conditions 100 photographs were taken.

\section{Surface classification}

The observed cartilage surface was classified using a classifications system inspired on the methods described by Juverlin et al. ${ }^{10}$ and Hong and Henderson. ${ }^{11}$ The need to introduce modifications in these classification systems was justified by the use of different animal models and different electron microscopes. It was desired to preserve the main structure of the classification described by the above-men- tioned authors to avoid ambiguity between the studies.

Four categories were used:

1. Surface contour: even (a.1), slightly uneven (a.2), hillocky (a.3), folded (a.4)

2. Surface quality: smooth (b.1), rough (b.2), small knobs (b.3), big knobs (b.4), leafy (b.5)

3. Splits: intact surface (c.0), superficial splits (c.1), deep splits (c.2)

4. Lacunae: no lacunae (d.0), filled lacunae (d.1), empty lacunae (d.2)

Only one observer performed the classification in order to reduce possible mistakes and differences.

\section{RESULTS}

Images obtained with the ESEM confirmed most of the general surface pattern classically described using a conventional SEM. One hundred photographs were obtained at $250 \times$, observing an area in each photograph equivalent to $0.1172 \mathrm{~mm}^{2}$.

Generally, the joint surface studied appeared uniformly smooth from center to edge (Fig. 1). However, it was possible to detect, in some specific locations, a pattern of hollows and prominences as described by Juverlin et al. ${ }^{10}$ and Hong and Henderson ${ }^{11}$ (Fig. 2).

Even/smooth cartilage surfaces could always be observed in the center portions (loading areas) of each disk. Slightly uneven surfaces were generally peripheral to the even/smooth surfaces. These were transitional areas between the even/smooth and slightly uneven areas.

Hillocky surfaces were generally located at nonspecific locations. These areas were usually rough or knobby, but never smooth. A very low incidence of fractures was detected within the superficial layer.

No fibrous surface as described by Juverlin et al. $^{10}$ and Hong and Henderson ${ }^{11}$ was detected in our experiments.

\section{DISCUSSION}

The investigation of articular cartilage surface by conventional scanning electron mi- 


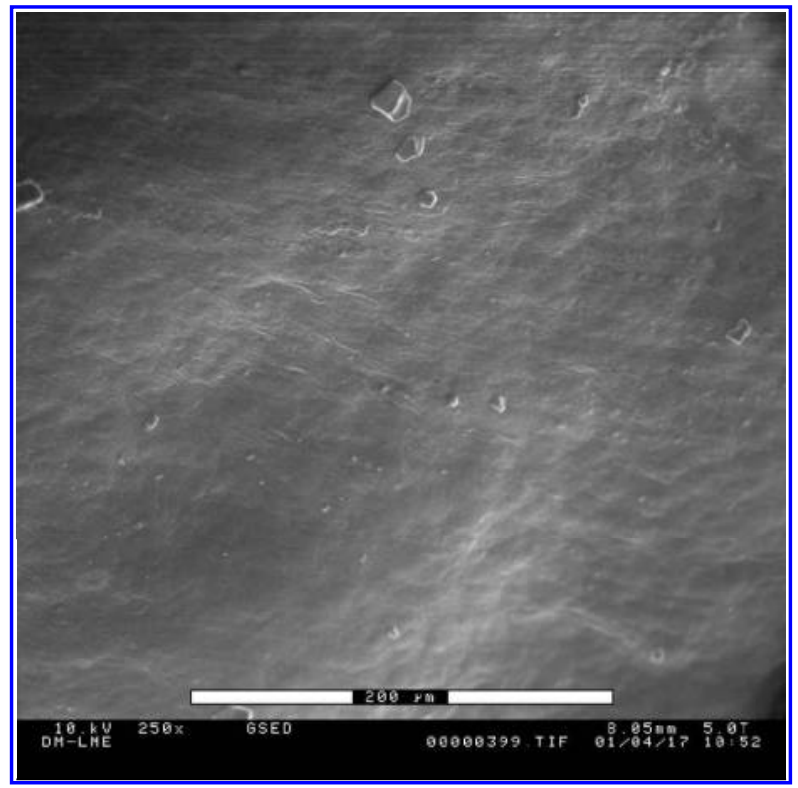

FIG. 1. ESEM view, showing the surface of a weightbearing area of the femoral condyle presenting a smooth surface with no roughness or splits.

croscopy has been criticized on physical and biological grounds. Preparations for scanning electron microscopy must be dry since they are viewed under high vacuum. Then, the dry material is coated with a thin electrically conductive metal such as gold/palladium alloy to prevent surface charging during scanning. Each of these preparative steps can presumably introduce artifacts. ${ }^{8}$

Undesirable effects of these procedures during the study of the morphology of the cartilage have been reported since very early in the beginning of the SEM. ${ }^{12}$

As an alternative to the chemical fixation, some vapor-producing samples can be prepared using cryofixation. ${ }^{713}$ However, even the most thorough methods of rapid freezing or cryogen jet freezing can chill without observable ice crystal damage on some surface layers, ${ }^{8}$ which may be a source of artifacts in examining a hydrated tissue as cartilage. ${ }^{14,15}$

The ESEM permits the study of biological samples in their natural hydrated state without conventional preparation techniques, providing high-resolution imaging at 10 Torr chamber pressure, eliminating the requirement for high vacuum in the SEM chamber. ${ }^{9}$

Because of the high proportion of water presented in the cartilage, it was decided that the ESEM is an appropriate tool for the study of this tissue. Cartilage surface irregularities were demonstrated and classified using a four-category system, based on the grading systems published by Juverlin et al. ${ }^{10}$ and Hong and Henderson. ${ }^{11}$

Juverlin et al. ${ }^{10}$ developed a classification system of articular cartilage for contour (even, slightly uneven, hillocky, folded, fibrous, and unclassified), quality of surface (smooth, slightly rough, rough, knobby, striated/leafy, and unclassified), and surface splits (intact, superficial, deep, and unclassified) to study the relative area changes following experimental treatment. The knobby surfaces described by Juverlin et al. ${ }^{10}$ are thought to be produced by underlying chondrocyte lacunae. Chondrocyte lacunae are also thought to produce the tertiary hollows of Longmore's classification system. The cause of these different presentations, elevations versus hollows, is controversial. Wigren and $\mathrm{Wik}^{16}$ reported oval depressions of 20-30 $\mu \mathrm{m}$ in diameter in rabbit articular cartilage, with the number of depressions decreasing after immobilization. By contrast, Jozsa et al. ${ }^{17}$ reported that immobilizing rat knee joints produced an increase in the number of depressions. They attributed this finding to the necrotic effect on chondrocytes, with the collapsing superficial layer producing empty pits on the cartilage surface.

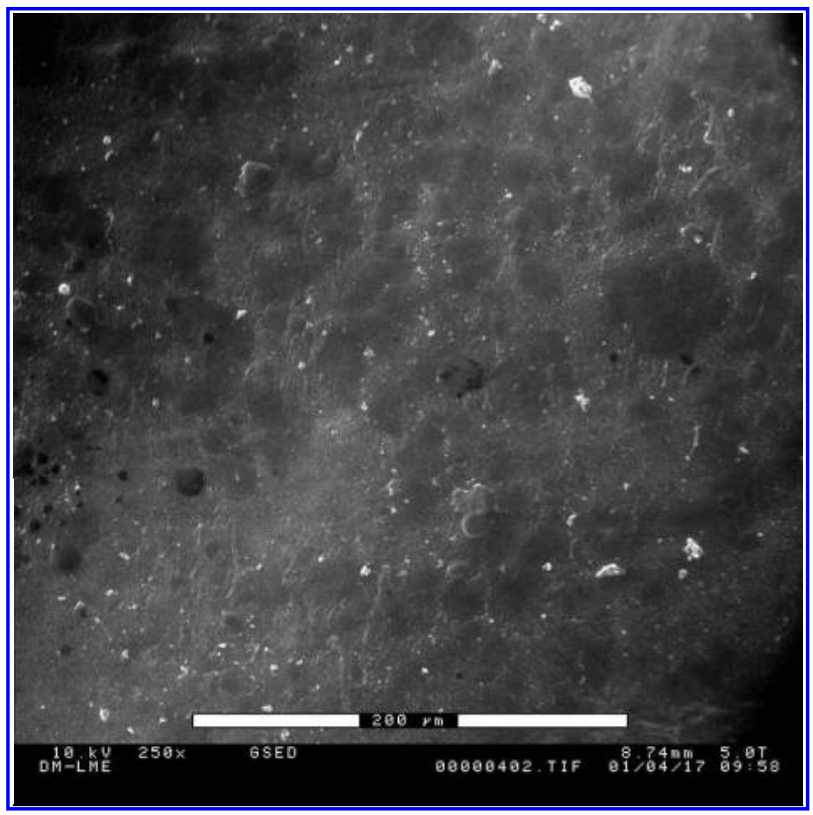

FIG. 2. Another view of the fresh articular surface using the ESEM. It is possible to distinguish hillocks and knobs as described by Juverlin et al. ${ }^{10}$ 
In 1996 Hong and Henderson ${ }^{11}$ considered it necessary to make some modifications in this system, not using the "fibrous surface" category because they did not observe that feature in their experiments. Similarly, it was not necessary to label any surface either as "unclassified" or as "striated."

In this study, we did not observed any split in the articular surface of osteochondral disks. For that reason we agree with Hong and Henderson, ${ }^{11}$ considering that that feature is likely a histological artifact.

The ESEM is a useful tool to obtain high-resolution images of fresh articular cartilage surface appearance without either employing fixation methods or exposing the specimen to extreme vacuum conditions, reducing the risk of introducing artifacts within the specimen. For all these reasons it could become a useful tool for quality control of the preservation process of osteochondral allografts in a musculoskeletal tissues bank and for determining changes in the surface of hyaline cartilage in clinical and experimental joint disease.

\section{ACKNOWLEDGMENTS}

This work was supported by a grant from the Transplant Services Foundation (TSF) of Barcelona (Spain). No benefits in any form have been received or will be received from a commercial party related directly or indirectly to the subject of this article. The experiments presented in this work comply with the current laws of Catalonia, Spain, and the European Union.

\section{REFERENCES}

1. Dowson D, Walker PS, Longfield MD, et al. An investigation of the friction and lubrication in human joints. Proc Inst Mech Eng. 1968;182:68.

2. McCall JG. Scanning electron microscopy of articular surfaces. Lancet. 1968;2:1194.

3. Gardner $\overline{\mathrm{DL}, \mathrm{M}} \mathrm{cGillivray} \mathrm{D.} \mathrm{Surface} \mathrm{structure} \mathrm{of} \mathrm{ar-}$ ticular cartilage. Ann Rheum Dis. 1971;30:10-14.

4. Gardner DL, Woodward DH. Scanning electron microscopy and replica studies of articular surfaces of guinea-pig synovial joints. Ann Rheum Dis. 1969;28: 379-391.
5. Inoue H, Kodama T, Fujita T. Scanning electron microscopy of normal and rheumatoid articular cartilages. Arch Histol Jpn. 1969;30:425-435.

6. Gardner DL, O'Connor P, Oates K. Low-temperature scanning electron microscopy of dog and guinea-pig hyaline articular cartilage. I Anat. 1981;132:267-282.

7. Kobayashi S, Yonekubo S, Kurogouchi Y. Cryoscanning electron microscopic study of the surface amorphous layer of articular cartilage. I Anat. 1995;187: 429-444.

8. Hayat MA. Chemical fixation. In: Principles and Techniques of Electron Microscopy. Biological Applications, 3rd ed. London: Macmillan Press; 1989:1-78.

9. Padros-Fradera E, Creus-Martinez M, Padros-Serrat $\mathrm{JL}$, et al. Una nueva etapa en la investigacion odontologica con el microscopio electronico de barrido ambiental (ESEM). RCOE 1999;4:73-80.

10. Jurvelin J, Kuusela T, Heikkilä R, et al. Investigation of articular cartilage surface morphology with a semiquantitative scanning electron microscopic method. Acta Anat. 1983;116:302-311.

11. Hong SP, Henderson C. Articular cartilage surface changes following immobilization of the rat knee joint. Acta Anat. 1996;157:27-40.

12. Clarcke IC. Articular cartilage: A review and scanning electron microscope study. I Bone Joint Surgery Br. 1971;53:732-750.

13. Kobayashi S, Yonekubo S, Kurogouchi Y. Cryoscanning electron microscopic study of loaded articular cartilage with special reference to the surface amorphous layer. I Anat. 1996;188:311-322.

14. Dempsey GP, Bullivant S. A copper block method for freezing non-cryoprotected tissue to produce ice-crystal-free regions for electron microscopy. I. Evaluation using freeze-substitution. JMicrosc. 1976;106:251-260.

15. Bald WL, Robards AW. A device for the rapid freezing of biological specimens under precisely controlled and reproducible conditions. J Microsc. 1978;112:3-15.

16. Wigren A, Wik O. The influence of hyaluronic acid on immobilized knees. An experimental study on adult rabbits. Ups J Med Sci Suppl. 1974;16S:1-27.

17. Jozsa L, Jarvilen M, Kannus P, Reffy A. Fine structural changes in the articular cartilage of the rat's knee following short-term immobilization in various positions: a scanning electron microscopical study. Int Orthop. 1987;11:129-133.

Address reprint requests to: Jose A. Carbonell, M.D., Ph.D. Bank of Musculoskeletal Tissues Institute of Locomotor System Clinic Hospital of Barcelona University of Barcelona Villarroel, 170 08036 Barcelona, Spain 


\section{This article has been cited by:}

1. Naresh Kumar Singh, Gaj Raj Singh, Dong Kee Jeong, Sung Jin Lee. 2013. Healing of full-thickness articular cartilage defects treated with cultured autologous chondrogenic satellite cells isolated from chondral stem cell niche in rabbits. Journal of Surgical Research 183, 629-638. [CrossRef]

2. Jane Desrochers, Matthias A. Amrein, John R. Matyas. 2010. Structural and functional changes of the articular surface in a post-traumatic model of early osteoarthritis measured by atomic force microscopy. Journal of Biomechanics 43, 3091-3098. [CrossRef]

3. S. Sastre, S. Suso, J. M. Segur, G. Bori, J. A. Carbonell, E. Agustí, M. Nuñez. 2009. Hyaline cartilage surface study with an environmental scanning electron microscope. An experimental study. Journal of Materials Science: Materials in Medicine 20, 2181-2187. [CrossRef]

4. N. K. Singh, G. R. Singh, P. Kinjavdekar, A. K. Sharma, T. R. Mohanty, S. Kumar, H. S. Chae, Y. M. Yoo, C. N. Ahn. 2007. Articular Cartilage Repair with Autografting Under the Influence of Insulin-Like Growth Factor-1 in Rabbits. Journal of Veterinary Medicine Series A 54:10.1111/jva.2007.54.issue-4, 210-218. [CrossRef]

5. Livio Muscariello, Francesco Rosso, Gerardo Marino, Antonio Giordano, Manlio Barbarisi, Gennaro Cafiero, Alfonso Barbarisi. 2005. A critical overview of ESEM applications in the biological field. Journal of Cellular Physiology 205:10.1002/jcp.v205:3, 328-334. [CrossRef] 